\title{
Manifestaciones gastrointestinales y hepáticas de COVID-19 en niños
}

\section{Gastrointestinal and hepatic manifestations of COVID-19 in children}

\author{
Mónica Villanueva Ch. ${ }^{a}$, Rossana Faundez H. ${ }^{b}$, Marcela Godoy ${ }^{\mathrm{c}}$ \\ aUnidad de Gastroenterología Pediátrica Clínica Alemana de Santiago. Unidad de Gastroenterología Pediátrica Hospital Clínico San Juan de Dios \\ Facultad de Medicina Universidad de Chile. Santiago, Chile \\ bUnidad de Gastroenterología Pediátrica Hospital Clínico San Juan de Dios. Facultad de Medicina Universidad de Chile. \\ Unidad de Gastroenterología Pediátrica Clínica Santa María. Santiago, Chile \\ c Unidad de Gastroenterología Pediátrica. Servicio de Pediatría Hospital Clínico San Borja Arriarán. Rama de Gastroenterología de la Sociedad \\ Chilena de Pediatría. Santiago, Chile
}

Recibido: 8 de mayo de 2020; Aceptado: 13 de mayo de 2020

\section{¿Qué se sabe del tema que trata este estudio?}

SARS-CoV-2 es principalmente un patógeno respiratorio que también afecta el tracto gastrointestinal. Un 10\% de los niños desarrollan diarrea y vómitos. Pacientes asintomáticos especialmente niños pueden transmitir la enfermedad. Pacientes con enfermedad severa tienen hipertransaminasemia (40-60\%) en comparación con asintomáticos o enfermedad leve (18-25\%).

\section{¿Qué aporta este estudio a lo ya conocido?}

Este estudio alerta sobre las manifestaciones gastrointestinales y hepáticas que se han descrito en pacientes COVID-19 (+) para aumentar el índice de sospecha, realizar diagnóstico precoz y reconocer complicaciones de la enfermedad.

\section{Resumen}

SARS-CoV-2 es un virus de alta estabilidad ambiental. Es principalmente un patógeno respiratorio que también afecta el tracto gastrointestinal. El receptor ACE2 es el principal receptor de SARSCoV-2, hay evidencia de su elevada presencia en intestino, colon y colangiocitos; igualmente se encuentra expresado en hepatocitos pero en menor proporción. SARS-CoV-2 tiene un tropismo gastrointestinal que explica los síntomas digestivos y la diseminación viral en deposiciones. Las características de SARS-CoV-2 incluyen a la proteína S (Spike o Espícula) que se une de forma muy estable al receptor ACE2. La infección por SARS-CoV-2 produce disbiosis y alteraciones en el eje pulmónintestino. A nivel intestinal y hepático produce una respuesta Linfocitos $\mathrm{T}$ evidente y una respuesta de citocinas que producirían daño intestinal inflamatorio. Las manifestaciones a nivel intestinal en orden de frecuencia son pérdida de apetito, diarrea, náuseas, vómitos y dolor abdominal. Éste último podría ser un marcador de gravedad. En niños la diarrea es habitualmente leve y autolimitada. A nivel hepático la hipertransaminasemia ocurre en $40-60 \%$ de los pacientes graves. SARS-CoV-2 puede permanecer en deposiciones un tiempo más prolongado que en secreciones respiratorias, este hallazgo
Palabras clave:

Coronavirus;

COVID-19;

Diarrea;

Hipertransaminasemia; SARS-CoV-2 
influiría en la diseminación de enfermedad. En esta revisión se destaca la importancia de efectuar un reconocimiento precoz de las manifestaciones gastrointestinales y hepáticas, aumentar el índice de sospecha, efectuar un diagnóstico oportuno y reconocer eventuales complicaciones de la enfermedad. La potencial transmisión fecal oral puede influir en la diseminación de enfermedad. Reconocer este hallazgo es importante para definir aislamiento.

\begin{abstract}
SARS-CoV-2 is a high environmental stable virus. It is predominantly a respiratory pathogen that also affects the gastrointestinal tract. The ACE 2 receptor is the main receptor of SARS-CoV-2, with evidence of its high presence in the intestine, colon and cholangiocytes, and, in smaller proportion, in hepatocytes. SARS-CoV-2 has a gastrointestinal tropism that explains digestive symptoms and viral spread in stools. The characteristics of this virus include the $S$ (Spike) protein that binds very stably to the ACE-2 receptor and, at the same time, SARS-CoV-2 produces dysbiosis and alterations in the gut-lung axis. It produces a clear T-cell response and a cytokines storm in the intestine and liver that would produce inflammatory bowel damage. Intestinal manifestations by order of frequency are loss of appetite, diarrhea, nausea and vomiting, and abdominal pain, where the latter could be a severity marker. In children, diarrhea is the most frequent symptom, usually mild and self-limiting. In the liver, hypertransaminasemia occurs in severe patients ranging from 40 to $60 \%$. SARS-CoV-2 can remain in stools longer than in respiratory secretions, which would influence the spread of disease. This article highlights the importance of an early diagnosis of gastrointestinal and hepatic manifestations, increase the index of suspicion, make a timely diagnosis, and recognize eventual complications of the disease. The potential oral-fecal route of transmission may influence the disease spread. Recognizing this finding is important to define isolation.
\end{abstract}

Keywords:

SARS-CoV-2;

Diarrhea;

Hypertransaminasemia; Fecal-Oral

Transmission

\section{Introducción}

SARS-CoV-2 es el séptimo coronavirus identificado con capacidad de infección humana ${ }^{1}$. En el año 2019 emergió como un nuevo betacoronavirus ${ }^{2}$. Es un virus monocatenario de ARN cuyo transmisor intermediario todavía no ha sido identificado ${ }^{1}$, es altamente contagioso y estable en el ambiente, se transmite predominantemente entre humanos ${ }^{3}$. Sus características genéticas muestran que $89 \%$ de su secuencia nuclear es similar a Bat SARS-CoVZXC21 y 82\% a SARS-CoV ${ }^{4}$. Puede afectar a personas de todas las edades con una alta tasa de infectividad, sabiendo que los niños pueden ser menos susceptibles ${ }^{1}$.

SARS-CoV-2 ha infectado al 14 de julio de 2020 a 13284292 personas a nivel global y ha originado 577.843 muertes $^{5}$. De ellos en Chile hay 319.493 infectados y 7.069 fallecidos, de ellos el 4,8\% de los infectados corresponden a menores de 15 años ${ }^{6}$.

Hay series que describen prevalencias de hasta $24,8 \%$ en población pediátrica ${ }^{1}$, donde niños menores de 3 años y con enfermedad cardiaca son los más frecuentemente afectados ${ }^{2}$.

El 14\% de la población adulta tiene manifestaciones severas y un 5\% tiene manifestaciones críticas (Falla respiratoria, shock séptico, falla orgánica múltiple), alcanza una mortalidad de $2,3 \%{ }^{7}$. En otra cohorte de pacientes, el 6\% de niños desarrolló enfermedad severa comparado con el 18,5\% de adultos ${ }^{8}$. En Chile al 12 de julio de 2020: 244 pacientes pediátricos han egresado de unidades de cuidados intensivos (240 vivos y 4 fallecidos), $62 / 244$ ha requerido soporte ventilatorio y 63/244 ha presentado PIMS/hipercoagulabilidad. Treinta y nueve pacientes menores de 20 años han fallecido (14 confirmados y 25 sospechosos) ${ }^{6}$. En general, los niños tienen síntomas más leves que los adultos y esto sugeriría el alto riesgo de que se comporten transmitiendo la enfermedad al ser asintomáticos ${ }^{2}$.

Aunque SARS-CoV-2 es principalmente un patógeno respiratorio, también afecta el tracto gastrointestinal. Aproximadamente el $10 \%$ de los niños con infección desarrollan diarrea y vómitos. Hay reportes de diarrea aislada que precede a la tos y la fiebre. La positividad prolongada SARS-CoV-2 en las heces aumenta la posibilidad de transmisión fecal-oral. Los individuos asintomáticos especialmente los niños pueden comportarse como transmisores de la enfermedad dado el menor índice de sospecha y por tanto menor oportunidad de detección ${ }^{7}$.

Por otro lado pacientes con enfermedad severa por SARS-CoV-2 presentan elevación de las transaminasas hasta en un 40-60\% en comparación con los que son asintomáticos o los que tienen enfermedad leve donde se eleva hasta en 18-25\% de los casos. Además, se 
han descrito algunos casos de disfunción hepática severa $^{9-11}$.

El objetivo de esta publicación es alertar sobre las manifestaciones gastrointestinales y hepáticas que se han descrito en pacientes COVID-19 (+) para aumentar el índice de sospecha, efectuar un diagnóstico oportuno y reconocer eventuales complicaciones de la enfermedad.

\section{Fundamentos Fisiopatológicos de afectación gastrointestinal y hepática}

SARS-CoV-2 es un patógeno primariamente respiratorio que puede producir un síndrome respiratorio severo agudo, pero es también un virus que puede afectar al tracto gastrointestinal (TGI).

¿Cómo es que un virus sin envoltura es capaz de sobrevivir al pH bajo del estómago y al efecto detergente de las sales biliares? Esto podría deberse a que comparte condiciones con otros coronavirus SARS; características como la glicosilación intensa de la proteína $S$, su evolución intrínseca a pH bajo y enzimas digestivas y también a la formación de un complejo estrecho con mucinas. Condiciones que además podrían explicar su gran estabilidad en el ambiente ${ }^{3}$.

El compromiso intestinal originado por SARSCoV-2 está explicado por varias razones. Primero, se ha establecido como un probable receptor celular para SARS-CoV-2 al receptor de la enzima convertidora de angiotensina 2 (ACE2) $)^{12}$, este receptor está asociado a un gen ligado a $\mathrm{X}$ lo que le da un dismorfismo sexual en hígado y tracto gastrointestinal, haciendo que la expresión genética de ACE2 presente notorias diferencias en su expresión entre hombres y mujeres, esta característica contribuiría a una manifestación clínica más severa en varones, fumadores y pacientes con EPOC que tienen mayor expresión de esta enzima ${ }^{3,13}$.

$\mathrm{Al}$ igual que en la mucosa respiratoria (En las células alveolares tipo II), el receptor de la enzima convertidora de angiotensina tipo 2 (ACE-2) y la serina proteasa transmembrana 2 (TMPRSS2) se coexpresan en el tracto gastrointestinal, específicamente en las células glandulares del esófago y en los enterocitos de la superficie apical de ileon y colon ${ }^{3,9,10}$. También se expresan en monocitos, macrófagos y en células endoteliales ${ }^{9}$.

Ambas proteínas son claves en la fisiopatología de la enfermedad. Su coexpresión en la misma célula es crítica para permitir la entrada del virus ${ }^{9}$.

SARS-CoV-2 codifica 4 proteínas estructurales: la proteína $S$ (spike protein o espícula), la proteína $\mathrm{E}$ (envelope), la proteína M (membrane) y la proteína $\mathrm{N}$ (nucleocápside). Es la proteína S de SARS-CoV-2 la que tiene una alta afinidad por ACE2 y es la principal responsable de la invasión viral ${ }^{1,3,14}$.
Durante la maduración viral, la proteína S es glicosilada y dividida en dos partes S1 y S2. La proteína S1 es esférica y está principalmente involucrada en el reconocimiento y unión del virus a las células hospederas. S2 es capaz de promover la fusión del virus con la membrana celular ${ }^{14}$. Gracias a estas características SARS-CoV-2 tiene una alta eficiencia al unirse a las células lo cual podría explicar su alto porcentaje de transmisión ${ }^{10}$.

Después de la entrada del virus, el RNA específico del virus y las proteínas son sintetizadas en el citoplasma celular para producir nuevos viriones, los cuales son liberados al tracto gastrointestinal ${ }^{10}$.

SARS-CoV-2 por lo tanto tiene un tropismo gastrointestinal que explica los síntomas digestivos y la diseminación viral en las deposiciones ${ }^{9}$. La diarrea asociada a SARS-CoV-2 podría estar asociada a proteínas o toxinas producidas durante la replicación viral ${ }^{15}$, otra posibilidad es que se produzca inflamación intestinal mediada por linfocitos $\mathrm{T}$.

A nivel intestinal la microbiota tiene un rol importante, se ha propuesto que SARS-CoV-2 causaría disbiosis; la razón está en que en condiciones fisiológicas el receptor de ACE2 en el intestino serviría para la expresión del transportador de aminoácidos $\mathrm{B}^{0} \mathrm{AT} 1$. Esta asociación receptor $\mathrm{ACE} 2-\mathrm{B}^{\circ} \mathrm{AT} 1$ permite la entrada del triptófano al enterocito, el triptófano se regula vía mTOR, que es una vía de activación de la secreción de péptidos antimicrobiales que definen de forma importante la composición de la microbiota intestinal. Cuando este receptor ACE2 está ocupado por SARS-CoV-2, el triptófano no puede ser metabolizado eficientemente, alcanzando una secreción aberrante de péptidos antimicrobiales y consecuentemente una disbiosis que confiere susceptibilidad a la inflamación del intestino delgado ${ }^{16}$.

La microbiota intestinal y la respiratoria se desarrollan simultáneamente después del nacimiento; en individuos sanos estas comunidades son predominantemente phyla, bacteroidetes y firmicutes. La microbiota intestinal influencia la microbiota pulmonar y también la respuesta inmune; en infección respiratoria aguda se produce un estado disbiótico que produce un incremento en la prevalencia de bacterias y metabolitos bacterianos, tales como ácidos grasos de cadena corto (SCFA) ${ }^{17,18}$. Este efecto es llamado "eje intestinopulmón”, lo que explicaría porque pacientes con neumonía por SARS-CoV-2 tienen a menudo síntomas digestivos $^{19}$.

En la fisiopatología del compromiso hepático juegan un rol las células del ducto biliar las que son conocidas por jugar un importante rol en la regeneración hepática y en la respuesta inmune; éstas células así como los hepatocitos expresan ACE2 ${ }^{10}$. La expresión del receptor ACE2 en colangiocitos es veinte veces 
mayor en hepatocitos (donde alcanza el 2,6\%) muy similar al de las células de tipo alveolar tipo 2. Por otro lado, las células de Kupffer y endoteliales del hígado no expresan ACE2 ${ }^{20}$.

SARS-CoV-2 se une a ACE2 en los colangiocitos y esta unión podría producir un daño directo del ducto biliar; los hepatocitos no serían un target del virus, no al menos a través de ACE2 $2^{9,20}$. SARS-CoV-2 causaría injuria al producir un aumento en la expresión de ACE2, causando una proliferación compensatoria de hepatocitos derivados desde células epiteliales del ducto biliar ${ }^{19}$.

Por lo tanto las alteraciones hepáticas observadas no se deberían necesariamente a injuria directa al hepatocito. Podrían estar causadas también por drogas (Antibióticos, esteroides y antivirales) o por la respuesta inflamatoria sistémica inducida por la neumonía ${ }^{11,20}$.

Tanto en Tracto gastrointestinal como en hígado el virus gatilla una respuesta células $\mathrm{T}$ que conduce a su activación, diferenciación y producción de citocinas asociadas a sus estirpes ${ }^{9}$, produciendo una tormenta de citoquinas "cytokine storm" manifestada por un incremento de respuesta TH17 y alta citotoxicidad de LTCD $8^{21}$.

La hipoxia isquémica secundaria a la falla respiratoria jugarían un rol en aquellos pacientes con un severo daño hepatocelular ${ }^{10,21}$.

Biopsias postmortem de un paciente fallecido con SARS-CoV-2 mostraron moderada esteatosis microvesicular y actividad portal y lobular leve, indicando que podría haber sido causada por el infección por SARS-CoV-2 o por drogas (Injuria hepática inducida por drogas) $)^{21,22}$.

Otro mecanismo podría ser la reactivación de enfermedades hepáticas preexistentes conocidas o no. Hay drogas que por ejemplo pueden reactivar la actividad de Virus Hepatitis B. No es del todo conocido si SARS-CoV-2 puede exacerbar enfermedades colestásicas previas ${ }^{21}$.

\section{Transmisión fecal oral}

La transmisión humano a humano puede ocurrir en diferentes formas: secreciones respiratorias, aerosoles, superficies contaminadas y también mediante deposiciones $^{23}$, ya que SARS-CoV-2 ha sido detectada en tracto gastrointestinal, saliva y orina ${ }^{24}$.

Se ha detectado SARS-CoV-2 en deposiciones de hasta $50 \%$ de pacientes. En muchos casos esta detección no coincidió con la presencia de síntomas digestivos $^{10}$.

Xing ${ }^{25}$, describió a tres pacientes pediátricos con SARS-CoV-2 (donde sólo uno de ellos tenía síntomas digestivos); al realizar PCR tanto en hisopado faríngeo como en deposiciones se demostró un clearance viral que alcanzaba a ser de dos semanas en tracto respiratorio y mayor a 4 semanas en deposiciones.

En otro estudio donde se describe una cohorte de 59 pacientes adultos en Hong Kong y donde se realizó además una revisión sistemática y metaanálisis se detectó SARS-CoV-2 en deposiciones en un 15,3\%, incluyendo pacientes sin síntomas gastrointestinales. En la revisión sistemática hasta el $48 \%$ de pacientes tuvieron deposiciones con RNA de SARS-CoV-2 durante la enfermedad ${ }^{1}$.

La persistencia de RNA en deposiciones fue más prolongada que en muestras respiratorias, apareciendo de forma tan precoz como 2-5 días desde el inicio de enfermedad, permaneciendo positiva hasta por más de 3 semanas de iniciada. En estos estudios entre el 70,3\% y $82 \%$ de pacientes tuvieron RNA SARS-CoV-2 en deposiciones con muestra respiratoria negativa ${ }^{1,7,26}$. Lo que es incierto es el significado de este hallazgo, si son partículas de virus vivo o sólo fragmentos de $\mathrm{RNA}^{1,27}$. Los pacientes tratados con corticoides tuvieron positividad más prolongada en deposiciones ${ }^{27}$, y pacientes con diarrea al inicio de enfermedad tuvieron mayor carga viral en deposiciones en relación a los pacientes sin diarrea ${ }^{1}$.

A partir de esta descripción en algunos hospitales se incluyó el testeo de ácido nucleico en muestra fecal como un estándar para suspender aislamiento. Esta observación es relevante considerando la posibilidad de diseminación viral en centros preescolares y escolares ${ }^{25}$.

Por lo tanto la transmisión fecal-oral debe ser considerada independientemente de la presencia de síntomas gastrointestinales ${ }^{7,9,10,14}$. Deben hacerse esfuerzos para impedir la diseminación por esta vía cuando se reanuden las actividades en guarderías y centros preescolares y escolares, más aun en los países en desarrollo ${ }^{25}$.

\section{Manifestaciones gastrointestinales}

Los síntomas clásicos de SARS-CoV-2 son fiebre, tos, fatiga, mialgias y disnea. Menos del 10\% de niños infectados desarrollan síntomas gastrointestinales.

La fiebre es el síntoma más común $(92,8 \%)$ seguido por tos $(69,8 \%)$, disnea $(34,5 \%)$, mialgia $(27,7 \%$; y cefalea $(7,2 \%)^{28}$.

En pediatría 10\% de niños son asintomáticos, 44$50 \%$ tienen fiebre y el $82 \%$ tuvieron un contacto cercano $^{2}$.

La infección por SARS-CoV-2 puede causar gastritis y enteritis aguda, evidenciadas por vómitos, náuseas, dolor abdominal y diarrea ${ }^{14}$, descritas con frecuencias y tiempos de aparición variables desde el inicio de la 
enfermedad. La anorexia podría ser causada por el estado inflamatorio, hipoxia, depresión, reacciones adversas a drogas terapéuticas ${ }^{27}$. Para la aparición de síntomas gastrointestinales no parecen haber condiciones coexistentes, condicionantes o previas ${ }^{10}$.

En adultos se han descrito síntomas digestivos en pacientes con SARS-CoV-2 en varias series. El primer caso SARS-CoV-2 positivo en USA tuvo historia de náuseas y vómitos al cuarto día de inicio de enfermedad y diarrea al día 6 que se autolimitó ${ }^{29}$.

$\operatorname{Pan}^{19}$, describe que el $50 \%$ de pacientes presenta uno o más síntomas digestivos, de ellos un 3\% presentó síntomas digestivos en ausencia de síntomas respiratorios. Jin reporta síntomas gastrointestinales en 74 de $651(11,4 \%)^{14}$, Nobel en Nueva York reporta hasta $35 \%(97 / 278)^{30}$ y Zili Zhou describió hasta $26 \%{ }^{31}$.

Luo realizó un estudio en Wuhan, en 1141 pacientes durante un periodo de 7 semanas. De ellos un 16\% (183) presentó sólo síntomas gastrointestinales. Los síntomas más comunes incluyeron pérdida de apetito $(98 \%)$, náuseas $(73 \%)$ y vómitos $(65 \%)$, es decir habían síntomas digestivos en casi $2 / 3$ de pacientes. La diarrea se presentó en $37 \%$ y dolor abdominal en $25 \%{ }^{32}$.

En adultos estos síntomas presentan frecuencias variables en diferentes descripciones de grupos: Pérdida de apetito $(78,6 \%)$, vómitos $(65 \%-4,9 \%)$, diarrea (37\%-34\%- 24\%, 8,1\%, 6,1\%, 3-8\%) y dolor abdominal $(25 \%-1,9 \%)^{10,12,14,19,28,32}$. Lu en una cohorte de 171 niños reportó diarrea en $8,8 \%$ y vómitos en $6,4 \%$ de pacientes $^{33}$.

En la revisión sistemática realizada por Cheung donde se analizaron 60 estudios y 4.243 pacientes de todo el mundo, 18 estudios reportaron prevalencia de anorexia, 32 de nausea y vómito, 58 diarrea y 12 de dolor abdominal. La prevalencia acumulada de anorexia fue $26,8 \%$, de náuseas y vómitos $10,2 \%$, diarrea $12,5 \%$ y dolor abdominal/discomfort 9,2\% ${ }^{1}$.

Los síntomas gastrointestinales varían ampliamente durante el curso de la enfermedad. Se encontraron diferencias entre frecuencia de síntomas entre adultos y niños. La anorexia fue el síntoma digestivo más frecuente en adultos (39,9\%-50,2\%), mientras que la diarrea fue el síntoma más frecuente entre niños y adultos (2\%-49,5\%). El vómito fue más común 3,6\%-15,9\% vs $6,5 \%-66,7 \%$ en adultos. Hay sangrado gastrointestinal en el 4\%-13,7\%. Este estudio destaca el dolor abdominal como síntoma más frecuente entre los pacientes críticamente enfermos $(2,2 \%-6,0 \%)^{27}$.

En Chile, de acuerdo al Departamento de Epidemiología del Ministerio de Salud, con datos al 14 de julio de 2020 , de 200.000 casos el 16,3\% presentaba diarrea y $9,5 \%$ dolor abdominal ${ }^{6}$.

La diarrea es el síntoma digestivo más frecuente. En algunos pacientes es líquida hasta en 34,3\% y aparece como primer síntoma. Ocurre más frecuentemente 1 a 8 días después del comienzo de la enfermedad con una mediana de 3,3 días ${ }^{10,33}$, y es descrita como de bajo volumen, sin severidad clínica, típicamente de hasta tres veces al día ${ }^{19,27}$, con una duración promedio de 4 días (3-6 días) y la mayor parte de veces autolimitada ${ }^{14}$. La estrategia de manejo es la habitual sobretodo la hidratación ${ }^{27}$.

Al analizar casos en adultos con y sin síntomas gastrointestinales no se encontraron diferencias estadísticas significativas en cuanto a características demográficas (edad, sexo, raza, etnia, IMC, localización regional) o en evolución clínica; sin embargo del total de pacientes que tuvieron síntomas gastrointestinales solamente el 11\% del total presentó síntomas digestivos al ingreso mientras que el resto desarrollaron síntomas durante la hospitalización ${ }^{10,30}$. Los síntomas gastrointestinales parecieran ser más frecuentes por grupo familiar ${ }^{14}$.

Desde abril de 2020 en Reino Unido se han reportado casos de niños con estado inflamatorio multisistémico, caracterizado por un cuadro clínico con características de sindrome Shock tóxico y Kawasaki atípico y con historia de exposición a SARS-CoV-2. El dolor abdominal y los síntomas gastrointestinales se han descrito también como características comunes a esta nueva descripción clínica ${ }^{34}$.

\section{Endoscopía y Rectoscopia}

No es muy frecuente realizar procedimientos endoscópicos en estos pacientes; la endoscopía en general muestra una relativa normalidad ${ }^{15}$. Lin describió un caso de sangrado digestivo alto donde la endoscopía alta mostró múltiples erosiones y úlceras cubiertas por fibrina blanca y coágulos en tercio inferior de esófago, en esa zona se detectó SARS-CoV-2, las biopsias demostraron presencia del virus además en estómago, duodeno y recto $^{35}$.

Deben evitarse los procedimientos endoscópicos de rutina, ya que generan aerosoles, más aún en niños donde también está involucrada el manejo de la vía aérea, ya que los procedimientos en niños en general se realizan en paciente con vía aérea intubada 9 .

La histología muestra infiltrado linfocítico ocasional en el epitelio esofágico escamoso, abundante infiltrado plasmático y linfocitos con edema intersticial en el estómago, duodeno y lámina propia del recto $^{27}$.

Por microscopía electrónica se observaron partículas virales $(60-90 \mathrm{~nm})$ en ileon y colon, las que se ubican en la superficie apical de los enterocitos y raramente en las células glandulares. Se ubican especialmente en la superficie vellositaria. A nivel celular el virus se localiza en vesículas dentro del retículo endoplasmá- 
tico. Posiblemente hay liberación desde la membrana apical de los enterocitos, pero hay mínima disrupción de las células intestinales por el virus a pesar del tropismo. No hay evidencia de atrofia vellositaria a pesar de la adhesión viral y colonización ${ }^{15}$.

\section{Manifestaciones hepáticas}

Se ha descrito un grado variable de alteraciones en la función hepática ${ }^{10,20}$. Es común la elevación de transaminasas apareciendo hasta en un $40-60 \%$ en pacientes con enfermedad grave en comparación con los que son asintomáticos o con enfermedad leve donde se eleva hasta en $18-25 \%$ de casos $^{10,11,36}$. La elevación de transaminasas está presente más frecuentemente en hombres ${ }^{21}$.

Esta elevación de transaminasas va a menudo acompañada de Creatinkinasa (CK) y lactato deshidrogenasa (LDH) elevadas ${ }^{9}$. La elevación de CK y LDH concomitantes sugieren la posibilidad de que la miositis viral tuviera efecto en la elevación de GOT.

El número de pacientes con GPT (glutamato piruvato transaminasa) y GOT (glutamato oxalacetato transaminasa) elevada es significativamente mayor en pacientes con síntomas digestivos lo que sugiere que en estos pacientes ocurren diferentes grados de daño hepático ${ }^{19,31}$.

Los niveles de bilirrubina se duplican en infección severa hasta en un $10 \%-53 \%$ de pacientes $^{10,21}$. Esto probablemente esté relacionado con las células $\mathrm{T}$ autorreactivas provocadas por virus y la tormenta de citoquinas ${ }^{9}$.

El patrón colestásico es visto raramente y muchos reportes sugieren que la fosfatasa alcalina es normal ${ }^{10}$. La albúmina está disminuida en casos severos y es marcador de peor pronóstico ${ }^{21}$. En pacientes fallecidos por SARS-CoV-2, la incidencia de injuria hepática alcanza hasta $58 \%-78 \%{ }^{11}$. La disfunción hepática grave es poco común.

El daño hepático debe ser cuidadosamente monitorizado, ya que se han encontrado elevaciones de GPT y condiciones coexistentes en pacientes con COVID-19 con síntomas gastrointestinales ${ }^{14}$. Todo niño con SARS-CoV-2 y persistencia de transaminasas elevadas debiera ser investigado para otras causas de enfermedad hepática, y si son asintomáticos o con síntomas leves no deben ser hospitalizados ${ }^{9}$. En cambio se sugiere que pacientes con ictericia de reciente diagnóstico, GOT/GPT > 500 UI/L o descompensación hepática de inicio reciente deben ser hospitalizados. Las transaminasas moderadamente elevadas en la enfermedad SARS-CoV-2 no son una contraindicación para la terapia antiviral, pero requieren monitoreo regular de la función hepática ${ }^{11}$.

\section{¿Hay asociación entre síntomas digestivos y severidad clínica?}

En una revisión sistemática, un 17,6\% presentó síntomas gastrointestinales, el 11,8\% de ellos tuvo COVID-19 no severo y $17,1 \%$ tuvo COVID-19 severo. El análisis subgrupo muestra que la presencia de síntomas gastrointestinales estuvo asociada con un curso más severo de enfermedad ${ }^{1}$. Especialmente dolor abdominal.

\section{¿Se puede hablar de predicción de factores de riesgo para COVID-19 severo/crítico en pacien- tes con síntomas digestivos?}

Hay descripciones que no son concluyentes y que difieren mucho entre sí.

El grupo de Pan en China notó que la severidad de la enfermedad era mayor cuando había síntomas digestivos más pronunciados. Una posibilidad es que los síntomas digestivos indiquen una mayor carga viral y replicación dentro del tracto gastrointestinal. La otra posibilidad es que ante la ausencia de síntomas respiratorios la consulta haya sido tardía ${ }^{19}$.

La presencia de síntomas gastrointestinales estuvo asociada con un riesgo aumentado de hasta un 70\% de tener resultado positivo para SARS-CoV-2 y de tener una duración de enfermedad mayor (de hasta una semana más comparada con los asintomáticos digestivos $)^{30}$. Comparados con pacientes sin síntomas digestivos, hubo tiempo más prolongado de hospitalización y mayor compromiso hepático, incluido mayor tiempo de coagulación y mayor elevación de enzimas hepáticas.

En la medida que la severidad de enfermedad aumenta, los síntomas digestivos empeoran, pero no se encontraron diferencias significativas en cuanto a mortalidad $^{14,19}$.

\section{Comentario final}

De acuerdo a lo revisado, es clara la presencia de síntomas digestivos y hepáticos en pacientes infectados por SARS-CoV-2. Éste, coexiste en el tracto gastrointestinal y en el respiratorio, pero persiste por más tiempo en el tracto gastrointestinal. No hay claridad absoluta acerca del significado pronóstico de estos hallazgos.

Sin embargo; el significado de los síntomas gastrointestinales no debe ser subestimado. Es importante y urgente ser capaces de reconocer el espectro clínico de esta enfermedad. En especial, el reconocimiento de los síntomas digestivos y la potencial transmisión fecal oral que pueden influir en la diseminación de enfermedad. Su reconocimiento temprano permitirá identifi- 
cación temprana, triage y aislamiento adecuado. Una desinfección y adecuado manejo de deposiciones es crucial en regiones endémicas.

Esta revisión y recomendaciones se han elaborado basadas en la información actualmente disponible. Quedan aún más preguntas que respuestas con respec- to a SARS-CoV-2; es necesario actuar en consecuencia con la evidencia de la que disponemos.

\section{Conflicto de interés}

Los autores declaran no tener conflicto de intereses.

\section{Referencias}

1. Cheung KS, Hung IF, Chan PP, et al. Gastrointestinal Manifestations of SARS-CoV-2 Infection and Virus Load in Fecal Samples from the Hong Kong Cohort and Systematic Review and Meta-analysis. Gastroenterology. 2020. (20) doi: https://doi.org/10.1053/j. gastro.2020.03.065.

2. Zimmermann P, Curtis N, Coronavirus Infections in Children Including COVID-19 An Overview of the Epidemiology, Clinical Features, Diagnosis, Treatment and Prevention Options in Children. Pediatr Infect Dis J 2020;39:355-68.

3. Ding S, Liang TJ. Is SARS-CoV-2 Also an Enteric Pathogen with Potential Fecal-Oral Transmission: A COVID-19 Virological and Clinical Review. Gastroenterology. 2020. https://doi. org/10.1053/j.gastro.2020.04.052.

4. Murray KF, Gold BD, Shamir R, et al. COVID-19 and the Pediatric Gastroenterologist. J Pediatr Gastroenterol Nutr. 2020 Publish Ahead of Print DOI : 10.1097/ MPG.0000000000002730.

5. Coronavirus disease (COVID-19) Situation Report-103 Data as received by WHO from national authorities by 10:00 CEST. Julio 2020.

6. Departamento de Estadística al e Información de Salud. División de planificación sanitaria. Subsecretaría de Salud Pública. Cifras oficiales COVID-19 Chile al 14/07/2020. Encuesta nacional de Rama de Intensivo Pediátrico de SOCHIPE.

7. Sultan S, Lim JK, Altayar O, et al. AGA Institute Rapid Recommendations for Gastrointestinal Procedures During the COVID-19 Pandemic. Gastroenterology. 2020. https://doi.org/10.1053/j. gastro.2020.03.072.

8. Dong Y, Mo X, Hu Y, et al. Epidemiological Characteristics of 2143 Pediatric Patients With 2019 Coronavirus Disease in China. Pediatrics. DOI: 10.1542/peds.2020-0702.

9. Matthai J, Shanmugam N, Sobhan P. Indian Society Of Pediatric Gastroenterology HpAN, Pediatrics PGCOIAO. Coronavirus Disease
(COVID-19) and the Gastrointestinal System in Children. Indian Pediatr. 2020.

10. Agarwal A, Chen A, Ravindran N. Gastrointestinal and Liver Manifestations of COVID-19. Journal Of Clinical And Experimental Hepatology https://doi. org/10.1016/j.jceh.2020.03.001.

11. Xu L, Liu J, Lu M, Yang D, Zheng X. Liver injury during highly pathogenic human coronavirus infections. Liver Int. 2020;40(5):998-1004.

12. García-Salido A. Revisión Narrativa Sobre La Respuesta Inmunitaria Frente A Coronavirus: Descripción General, Aplicabilidad Para Sars-Cov2 E Implicaciones Terapeúticas, Anales de Pediatria (2020). https://doi.org/10.1016/j. anpedi.2020.04.016.

13. Pirola CJ, Sookoian S. COVID-19 and ACE2 in the liver and gastrointestinal tract: Putative biological explanations of sexual dimorphism, Gastroenterology (2020), doi: https:// doi.org/10.1053/j. gastro.2020.04.050.

14. Jin X, Lian JS, Hu JH, et al. Epidemiological, clinical and virological characteristics of 74 cases of coronavirusinfected disease 2019 (COVID-19) with gastrointestinal symptoms. Gut. 2020. doi:10.1136/gutjnl-2020-320926.

15. Leung WK, To KF, Chan PK, et al. Enteric involvement of severe acute respiratory syndrome-associated coronavirus infection. Gastroenterology. 2003;125(4):1011-7.

16. Perlot T, Penninger JM. ACE2 - from the renin-angiotensin system to gut microbiota and malnutrition. Microbes Infect. 2013;15(13):866-73.

17. Marsland B,Trompette A,The Gut-Lung Axis in Respiratory Disease, Ann Am Thorac Soc 2015; 12 (2):S150-6.

18. Dumas A, Bernard L, Poquet $\mathrm{Y}$, Lugo-Villarino G, Neyrolles O. The role of the lung microbiota and the gut-lung axis in respiratory infectious diseases. Cellular Microbiology. 2018;20:e12966. https://doi.org/10.1111/ cmi.12966.

19. Pan L, Mu M, Yang P, et al. Clinical Characteristics of COVID-19 Patients With Digestive Symptoms in Hubei, China: A Descriptive, Cross-Sectional, Multicenter Study. Am J Gastroenterol. 2020;115(5):766-73. https://doi. org/10.14309/ajg.0000000000000620.

20. Chai X, Hu L, Zhang. Specific ACE2 Expression in Cholangiocytes May Cause Liver Damage After 2019-nCoV Infection, https://doi. org/10.1101/2020.02.03.931766.

21. Sun J, Aghemo A, Forner A, Valenti L. COVID-19 and liver disease. Liver Int. 2020 .doi: 10.1111/LIV.14470.

22. Xu Z, Shi L, Wang Y, et al. Pathological findings of COVID-19 associated with acute respiratory distress syndrome. Lancet Respir Med. 2020;8(4):4202. https://doi.org/10.1016/ S22132600(20)30076-X.

23. Homan M, Athiana I, Bontems P, et al. Gastrointestinal endoscopy in children and COVID 19 pandemic- ESPGHAN endoscopy SIG statement. 2020.

24. Guan WJ, Ni ZY, Hu Y, et al. Clinical Characteristics of Coronavirus Disease 2019 in China. N Engl J Med. 2020;382(18):1708-20.DOI: 10.1056/ NEJMoa2002032.

25. Xing $\mathrm{YH}, \mathrm{Ni} \mathrm{W}, \mathrm{Wu} \mathrm{Q}$, et al. Prolonged viral shedding in feces of pediatric patients with coronavirus disease 2019. J Microbiol Immunol Infect. 2020. https://doi.org/10.1016/j.jmii.2020.03.021.

26. Xu Y, Li X, Zhu B, et al. Characteristics of pediatric SARS-CoV-2 infection and potential evidence for persistent fecal viral shedding. Nat Med. 2020;26(4):502-5. doi.org/10.1038/s41591-020-0817-4.

27. Tian Y, Rong L, Nian W, He Y. Review article: gastrointestinal features in COVID-19 and the possibility of faecal transmission. Aliment Pharmacol Ther. 2020;51:843-51. https://doi.org/10.1111/ apt.15731.

28. Hormati A, Shahhamzeh A, Afifian M, Khodadust F, Ahmadpour S. Can COVID-19 present unusual GI symptoms? J Microbiol Immunol Infect. 2020. https://doi.org/10.1016/j. jmii.2020.03.020.

29. Holshue ML, DeBolt C, Lindquist S, et al. First Case of 2019 Novel Coronavirus in the United States. N Engl J Med. 2020;382(10):929-36. DOI: 10.1056/ NEJMoa2001191.

30. Nobel YR, Phipps M, Zucker J, et al. Gastrointestinal Symptoms and COVID-19: Case-Control Study from the United States. Gastroenterology. 
2020. doi: https://doi.org/10.1053/j. gastro.2020.04.017.

31. Zhou Z, Zhao N, Shu Y, Han S, Chen B, Shu X. Effect of gastrointestinal symptoms on patients infected with COVID-19, Gastroenterology (2020), doi: https://doi.org/10.1053/ j.gastro.2020.03.020.

32. Don't Overlook Digestive Symptoms in Patients With 2019 Novel Coronavirus Disease (COVID-19) Shihua Luo, Xiaochun Zhang, and Haibo Xu
Department of Radiology, Zhongnan Hospital of Wuhan University, Wuhan, Hubei Province, China Clinical Gastroenterology and Hepatology 2020 https://doi.org/10.1016/j.cgh.2020.03.043.

33. Lu X, Zhang L, Du H, et al. SARS-CoV-2 Infection in Children. N Engl J Med. 2020;382(17):1663-5.

34. Mahase E, Covid-19: concerns grow over inflammatory syndrome emerging in children.BMJ 2020;369:m1710 .doi: 10.1136/bmj.m1710.
35. Lin L, Jiang X, Zhang Z, et al. Gastrointestinal symptoms of 95 cases with SARS-CoV-2 infection. Gut. 2020. doi:10.1136/gutjnl-2020-321013.

36. Guan GW, Gao L, Wang JW, et al. [Exploring the mechanism of liver enzyme abnormalities in patients with novel coronavirus-infected pneumonia]. Zhonghua Gan Zang Bing Za Zhi. 2020;28(2):E002.

PMID: 32077659. DOI: $10.3760 / \mathrm{cma}$.j.is sn.1007-3418.2020.02.002. 